\title{
Congenital generalized hypertrichosis, Ambras type
}

INSERM

\section{Source}

INSERM. (1999). Orphanet: an online rare disease and orphan drug data base. Congenital generalized hypertrichosis, Ambras type. ORPHA:1023

Cong enital generalized hypertrichosis, Ambras type is an extremely rare type of hypertrichosis lanug inosa congenita, a congenital skin disease, that is characterized by the presence of vellus-type hair on the entire body, especially on the face, ears and shoulders, with the exception of palms, soles, and mucous membranes. Facial and dental anomalies can also be observed, such as triangular, coarse face, bulbous nasal tip, long palpebral fissures, delayed tooth eruption and absence of teeth. 